\title{
Who Cares About Being Gentle? The Impact of Social Identity and the Gender of One's Friends on Children's Display of Same-Gender Favoritism
}

\author{
Rachael D. Robnett • Joshua E. Susskind
}

Published online: 28 July 2010

(C) The Author(s) 2010. This article is published with open access at Springerlink.com

\begin{abstract}
This research assessed children's same-gender favoritism by examining whether children value traits descriptive of their own gender more than traits descriptive of the other gender. We also investigated whether children's proportion of same-gender friends relates to their samegender favoritism. Eighty-one third and fourth grade children from the Midwest and West Coast of the U.S. rated how well 19 personality traits describe boys and girls, and how important each trait is for their gender to possess. Results replicate and extend past trait assignment research by demonstrating that both genders valued same-gender traits significantly more than other-gender traits. Results also indicated that boys with many same-gender friends derogated feminine-stereotyped traits, which has implications for research on masculinity norms within maledominated peer groups.
\end{abstract}

Keywords Social identity · In-group · Gender norms · Masculinity

\section{Introduction}

The tendency to favor one's own gender over the other gender is pervasive during middle childhood. This tendency

R. D. Robnett $(\square)$

Department of Psychology, University of California, Santa Cruz, 1156 High Street,

Santa Cruz, CA 95064, USA

e-mail: rrobnett@ucsc.edu

\section{J. E. Susskind}

Psychology Department, 0505, University of Northern Iowa, Cedar Falls, IA 50614-0505, USA

e-mail: susskind@uni.edu has been documented across a variety of cultures, and some researchers have speculated that same-gender favoritism may be a universal feature of children's development (Maccoby 1998; Munroe and Romney 2006). During the past two decades, an increasing number of developmental psychologists have argued that same-gender favoritism and other intergroup processes play a key role in children's adherence to gender roles (Bigler and Liben 2007; Leaper 2000; Maccoby 1998; Powlishta 2004). According to this perspective, understanding children's same-gender favoritism and its corollaries is important because it provides insight into children's gender development.

Children's same-gender favoritism is often gauged by examining the number of positive and negative personality traits children allocate to their own gender versus the other gender (e.g., Powlishta et al. 1994; Powlishta 1995; Silvern 1977; Susskind and Hodges 2007; Zalk and Katz 1978). The results of these studies consistently demonstrate that children show same-gender favoritism by allocating more positive traits to their own gender than to the other gender. The present study built on past trait assignment research in two ways. First, we examined whether children from two geographic regions within the United States value the positive traits that they assign to their own gender more than the positive traits they assign to the other gender. This contrasts with past trait assignment research (e.g., Powlishta 1995; Susskind and Hodges 2007), which tends to focus on the relative number of traits that boys and girls assign to one another. We also examined whether our participants' proportion of same-gender friends was related to the strength of their same-gender favoritism. In making our predictions, we drew from social identity theory (Tajfel and Turner 1986; Turner et al. 1979; Turner and Reynolds 2004) with a particular emphasis on theoretical perspectives that emphasize the role intergroup processes play in 
children's attitudes toward out-group members (e.g., Abrams et al. 2003; Bigler and Liben 2007; Harris 1995; Leaper 2000; Maccoby 1998; Powlishta 2004).

Social psychology is replete with studies demonstrating that people tend to be biased in favor of the groups to which they belong. Known as in-group bias, this phenomenon is very robust. According to social identity theory, simply knowing that an out-group exists can evoke relatively strong in-group bias (Tajfel and Turner 1986; Turner et al. 1979). People so readily display in-group bias because they are motivated to possess a positive social identity. Social identity differs from personal identity in that personal identity is defined by characteristics unique to the individual, whereas social identity is derived from membership in social groups (Aberson et al. 2000; Tajfel and Turner 1986). People often perceive their group memberships as being an extension of their self-identity, so viewing the in-group positively can correspond to seeing the self positively.

According to social identity theory, one important factor that contributes to the achievement of a positive social identity is the perception of positive distinctiveness from the out-group in domains relevant to the in-group (Houston and Andreopoulou 2003; Lalonde 1992; Tajfel and Turner 1986; Turner et al. 1979). That is, people want to believe that their in-group is better than the out-group in areas important to the in-group's identity. The drive to achieve positive distinctiveness for the in-group can be seen in the way people allocate rewards to the in- and out-group in experimental conditions. When given the option of (a) distributing rewards in order to obtain the greatest gain for the in-group versus (b) distributing rewards in order to create the greatest difference between the in- and out-group, research has shown that children tend to follow the latter pattern of distribution (Vaughan et al. 1981). In other words, even if creating the greatest difference between the in- and out-group does not result in the maximum profit for the in-group, children still allocate rewards in the manner that will most differentiate the two groups.

Children begin to display in-group bias from an early age. Elementary school children's in-group bias was clearly documented in a series of studies conducted by Bigler and her colleagues (see Bigler and Liben 2007, for a review), which examined the effects of perceptually salient novel groups on children's in-group bias. In one such study, novel groups were created by assigning 6- to 9-year-old children from summer school classes to either a blue or yellow teeshirt group. In the experimental classrooms, the teachers enhanced the perceptual salience of the tee-shirt groups by regularly using them as a basis of categorization, whereas teachers in the control classrooms did not reference the teeshirt groups. Results demonstrated that children in the experimental classrooms showed stronger in-group favorit- ism than did children in the control classrooms, which suggests that the salience of group membership can enhance the strength of in-group favoritism (Bigler et al. 1997).

Research on naturally occurring (as opposed to experimentally manipulated) groups demonstrates that children show in-group bias based on a variety of salient characteristics (e.g., Powlishta et al. 1994; Verkuyten and Thijs 2001). Children's same-gender favoritism is particularly well documented (see Powlishta 2004, for a review). Developmental intergroup theory (Bigler and Liben 2007) provides insight into why social categories such as gender elicit such strong in-group bias in children. According to Bigler and Liben's (2007) model, children's likelihood of categorizing people based on a particular attribute is heightened when that attribute becomes salient. This categorization process can then lead to the development of stereotypes and prejudices about those who possess the salient attribute. Developmental intergroup theory proposes that several factors can heighten the salience of an attribute. Two of these factors are especially relevant to gender's salience: perceptual discriminability and explicit labeling and use. Perceptual discriminability pertains to gender's high visual salience: In most cases, children can immediately discern another person's gender simply by looking at her or him. Gender's perceptual discriminability is further enhanced by its status as a mutually exclusive dichotomy, which facilitates children's ability to make the "us" versus "them" distinction that is so critical to the display of ingroup bias (Powlishta 2004). Explicit labeling and use pertains to people's tendency to make functional use of gender as a social category (Bigler 1995; Bigler et al. 1997); gender is frequently used as a basis for grouping people (e.g., "Boys and girls, please line up for lunch.") and it is commonplace to refer to others' gender (e.g., "Son, go open the door for that woman."). Together these factors contribute to gender's primacy as a social category during childhood. In fact, Banaji and Prentice (1994) argued that gender is the most fundamental of all social identities.

Throughout the past three decades, the trait assignment method has been used a number of times to examine children's same-gender favoritism (Powlishta et al. 1994; Powlishta 1995; Silvern 1977; Susskind and Hodges 2007; Zalk and Katz 1978). In these studies, researchers gauge ingroup bias by asking children to allocate positive and negative personality traits either to their own gender or to the other gender. The typical pattern of findings in these studies is that children assign more positive traits and fewer negative traits to their own gender than to the other gender. For example, Powlishta (1995) conducted a study in which 8 - to 10 -year-old children rated 48 personality traits along a positivity-negativity spectrum and a masculinity-femininity spectrum. Results demonstrated that the more positive a 
trait was, the more children rated it as descriptive of their own gender. Results also indicated that children's samegender favoritism was more evident in their positive trait allocations than in their negative trait allocations, which is a relatively common finding in trait assignment research (e.g., Powlishta 1995; Susskind and Hodges 2007). Such a pattern of results is consistent with Brewer's (1999) concept of primacy of the in-group, which proposes that positive feelings about the in-group are an inherent feature of people's social identities and typically outweigh negative feelings about the out-group. For this reason, the present study focused on children's ratings of positive traits.

Most trait assignment research emphasizes the relative number of traits that boys and girls allocate to one another (e.g., Powlishta 1995; Silvern 1977; Susskind and Hodges 2007). The present study builds on these findings by assessing children's same-gender favoritism in a somewhat different manner. Specifically, we examined whether children value the traits they perceive as most descriptive of their own gender more than the traits they perceive as most descriptive of the other gender. Such an approach will allow for insight into the relationship between children's same-gender favoritism and their gender stereotypes.

The link between same-gender favoritism and gender stereotypes can be better understood by considering the overlap between gender schema theory and social identity theory. According to gender schema theory (Martin and Halverson 1981; Martin et al. 2002), children's motivation to adhere to gender role norms develops as their understanding of gender becomes more sophisticated. Once children come to understand that their gender is a fixed part of their identity, they become highly motivated to learn about and attend to gender role norms. As a result, children tend to disregard or avoid things that are associated with the other gender (Martin et al. 1995; Martin and Halverson 1981). This aspect of gender schema theory is consistent with social identity theory's (Houston and Andreopoulou 2003; Tajfel and Turner 1986, Turner et al. 1979) claim that people are motivated to value and adhere to the norms of the in-group while derogating the out-group and the norms associated with it (i.e., in-group bias or in-group favoritism). The present study therefore provided insight into the relationship between these two theoretical perspectives by examining whether children show in-group bias by differentially valuing traits they see as stereotypical of their own gender versus the other gender.

A second goal of the present study was to examine the relationship between children's same-gender favoritism and their proportion of same-gender friends. Children begin to show preferences for same-gender friends by age 3 or earlier and these preferences become stronger throughout middle childhood (see Maccoby 1998; Maccoby and Jacklin 1987). In fact, Maccoby and Jacklin (1987) found that children in early elementary school spent 11 times longer playing with same-gender friends than with othergender friends. This tendency does not appear to be unique to Western cultures; children's preference for same-gender peers has been documented in a variety of non-Western cultural communities as well. For example, Munroe and Romney (2006) found evidence of same-gender peer preferences in 3- to 9-year-old children from Nepal, Belize, Kenya, and Samoa, although the strength of this preference differed from one community to the next.

Several researchers have convincingly argued that samegender peer groups are one of the driving forces behind children's gender socialization (e.g., Leaper 2000; Maccoby 1998; Powlishta 2004). Perhaps most notably, Maccoby (1998) proposed that children's gender-typing can be better understood at the level of the group or dyad than at the level of the individual, and that children's same-gender peer groups may represent separate "male" and "female" subcultures. Other theorists (e.g., Leaper 2000; Powlishta 2004) have elaborated on Maccoby's perspective by more explicitly implicating intergroup processes as a factor that motivates children to adhere to the norms of same-gender peer groups. According to social identity theory (Aberson et al. 2000; Tajfel and Turner 1986; Turner and Reynolds 2004), people are motivated to assimilate the norms of the groups to which they belong. The norms of children's same-gender peer groups are largely consistent with traditional gender norms (Leaper 2000). Therefore, children with peer groups that are primarily comprised of samegender peers may adhere more strongly to gender role norms than do children with gender-balanced peer groups. Indeed, Martin and Fabes (2001) observed that as 3- to 6year-old children's exposure to same-gender friends increased over time, so too did their gender-typed behavior.

\section{Rationale for the Present Study}

The present study was designed to enhance the current understanding of children's same-gender favoritism. This is an important domain to study because same-gender favoritism and other intergroup processes have been linked to children's gender socialization and their adherence to gender norms (Leaper 2000; Maccoby 1998; Powlishta 2004). The goal of the present study was twofold. First, we sought to build on past trait assignment research by examining the extent to which children value the traits they allocate to their own gender and to the other gender. This contrasts with past trait assignment research, which tends to focus solely on the relative number of traits that boys and girls assign to one another. The design utilized in the present study will provide insight into the relationship between children's gender stereotypes and their display of same-gender favoritism. The second goal of this study was 
to examine the relationship between children's exposure to same-gender friends and their display of same-gender favoritism. As noted before, social identity theory (Tajfel and Turner 1986) proposes that people should be motivated to adhere to the norms of the groups to which they belong. Because the norms of children's peer groups typically align with traditional gender role norms (Maccoby 1998; Martin and Fabes 2001; Mehta and Strough 2009), it is plausible that children's exposure to same-gender peers will be related to their display of same-gender favoritism.

\section{Hypotheses}

Hypothesis 1 was derived from social identity theory's positive distinctiveness tenet (Tajfel and Turner 1986; Turner et al. 1979) and past research on children's samegender favoritism (e.g., Powlishta 1995; Susskind and Hodges 2007). Specifically, we predict that the traits children rate as most descriptive of their own gender will be more strongly valued than the traits children rate as most descriptive of the other gender. For example, we would expect boys to value strong (a stereotypically masculine trait) more than the trait gentle (a stereotypically feminine trait).

In accordance with the finding that children's gendertyped behavior is related to their membership in samegender peer groups (e.g., Leaper 2000; Maccoby 1998; Martin and Fabes 2001; Powlishta 2004), hypothesis 2 is that children with a high proportion of same-gender friends (hi-SGF) will value positive in-group traits more than do children with a low proportion of same-gender friends (lo-SGF). For example, we would expect hi-SGF girls to value the trait gentle (a feminine-stereotyped trait) to a greater extent than would lo-SGF girls.

Hypothesis 3 is similar to hypothesis 2, but it pertains to children's ratings of positive out-group traits rather than their ratings of positive in-group traits. Specifically, relative to lo-SGF participants, we expect hi-SGF participants to more strongly devalue traits perceived to be descriptive of the other gender. For example, we would expect hi-SGF boys to devalue the trait gentle (a feminine-stereotyped trait) to a greater extent than would lo-SGF boys.

\section{Method}

Participants

Prior to conducting this research, approval was obtained from school administrators, teachers, and the children's parent(s). Participants were 81 third and fourth grade students ( 45 boys and 36 girls) ranging in age from 8 to
11 years old ( $M=9$ years, 3 months, $S D=6$ months), which is the same age range that has been used in past trait assignment studies (e.g., Powlishta 1995; Susskind and Hodges 2007). Sixty-five participants identified as European American, nine identified as Latino/Latina, four identified as Asian American, and three identified as African American. The majority of participants $(80 \%)$ were recruited from two public elementary schools in the western United States. These schools were selected because the faculty and administrators were amenable to the research being conducted with their students. The remainder of the participants $(20 \%)$ were recruited from a universityaffiliated elementary school in the midwestern United States. This school was selected because the teachers and administrators have a working relationship with the second author. Although the participants' socioeconomic status was not directly assessed in the present study, all of the elementary schools included in this research were located in middle- or upper-middle-class neighborhoods.

\section{Measures}

Three questionnaires were created for this study. The first two questionnaires were comprised of 38 personality traits that were used by Susskind and Hodges (2007) in a similar study. These 38 traits were selected from a list of 48 traits that Powlishta (1995) originally used to assess same-gender favoritism in third and fourth grade children. Of the 38 traits used in the present study, 19 were rated as positive and 19 were rated as negative by Powlishta's (1995) sample. As noted before, the present study focused only on the children's ratings of the positive traits even though negative traits were also included in our questionnaires. We chose to focus on the positive traits because our preliminary analyses revealed that children's same-gender favoritism was more evident in their ratings of the positive traits than it was in their ratings of negative traits. This pattern of findings has also been obtained in similar studies (e.g., Susskind and Hodges 2007).

Of the 19 positive traits included in the present study, two were rated by both girls and boys in Powlishta's sample (1995) as masculine-stereotyped (strong and daring) and two were rated as feminine-stereotyped (gentle and affectionate). The remaining 15 positive traits were rated as gender-neutral or were attributed to different genders by girls and boys. A random number table was used to list the traits on the questionnaire in random order.

\section{Trait Importance Questionnaire}

Participants were presented with the following prompt: "If [members of the participant's gender] want to feel good about themselves, how good or bad is it to be like this?" 
Following the prompt was the list of 38 personality traits. Each trait was accompanied by a 7-point Likert-type scale. Traits could be rated as "very bad" (1), "bad" (2), "kind of bad" (3), "does not matter" (4), "kind of good" (5), "good" (6), or "very good" (7). Participants rated only members of their own gender.

\section{Gender Descriptiveness Questionnaire}

Participants were presented with the prompt "How many girls $[$ boys $]$ are like this?" Following the prompt was the list of 38 personality traits. Each trait was accompanied by 5 point Likert-type scale. Traits could be rated as describing "almost none" (1), "a few" (2), "some" (3), "most" (4), or "almost all" (5) members of the gender being evaluated. Participants completed this questionnaire twice, once to rate girls and once to rate boys. The order in which the two genders were rated was counterbalanced across participants.

\section{Same- and Cross-Gender Friendships Questionnaire}

A third questionnaire was created to gauge the number of same- and cross-gender friends each participant had in his or her class. We focused on participants' friends from class because it seemed like the clearest way to provide participants with concrete, specific parameters about who can and cannot be listed as a friend. Without these guidelines, it would have been difficult to know whom participants were including as friends. For example, some participants may have included family members, pets, or teachers in their list of friends, which would have been problematic from a theoretical standpoint.

At the beginning of this questionnaire, participants were provided with the following instructions: "Please think about your friends from class who are boys $[$ girls]. Now write down the names of your friends from class who are boys [girls]." These instructions were followed by a large space where participants could write down the names of their friends. All participants listed their same-gender friends first and their cross-gender friends second. Directly below the blank were the following instructions: "How many boys' [girls'] names did you just write down?" This question was immediately followed by a line where participants could record the number of names they had written down. These numerical values were used to calculate a proportion of same-gender friends to total (same- and cross-gender) friends for each participant. This proportion is the measure used in the forthcoming analyses.

\section{Procedure}

The first author and two research assistants who were familiar with the study administered the questionnaires over the course of two days. On the first day, one of the researchers went to the classroom and introduced her- or himself to all of the students. The researcher then took the participating students outside or to an empty classroom. (Students who had not received parental consent were left in the classroom with their teacher; this was the case for approximately $60 \%$ of the students across all participating classes). After seating the participants and handing out the survey, the researcher told the participants that adults need their help to understand how kids in elementary school think. The researcher then explained how to complete the same-gender friendship questionnaire, which was on the last page of the survey. Next, the researcher explained the instructions for the trait importance questionnaire. After all questions had been addressed, the researcher and the participants worked together to rate a gender-neutral trait that was not used in the present study (friendly). Participants were again asked if they had any questions. If there were no questions, the participants were instructed to begin and to raise their hand if they needed help. After the participants started the survey, the researcher responded to any questions on a one-on-one basis. Although most participants did not ask questions after beginning, several needed additional clarification. These questions were typically about what certain words meant, or how to spell their friends' names. Most participants finished within 15 to 20 minutes.

Approximately one week later, the researcher returned to administer the gender descriptiveness questionnaire. After handing out the questionnaire, the researcher read the instructions aloud and explained that some students would rate boys first, whereas some students would rate girls first. In all other respects, the day two procedure was identical to the day one procedure. Most participants completed this questionnaire within 20 to 25 minutes. When all participants had completed the questionnaire, they were debriefed about the basic purpose of the study and thanked.

\section{Results}

Preliminary Analyses and Scale Construction

We began by examining whether there were overall gender differences in how the participants responded to the questionnaires. This was done by conducting one-way multivariate analyses of variance (MANOVAs) on participants' trait ratings from each questionnaire. The first MANOVA revealed a significant gender difference in participants' ratings of trait importance, Wilks' $\lambda=.62, F$ $(19,61)=2.01, p=.02$, partial $\eta^{2}=.39$ (means and standard deviations for each trait are presented separately by gender in Table 1). The second and third MANOVAs examined whether there were gender differences in participants' 
Table 1 Mean (SD) trait importance ratings as a function of participant gender
Traits were rated on a scale ranging from 1 (the trait is very bad to have) to 7 (the trait is very good to have). Powlishta (1995) translated the personality traits into "kid friendly" language (e.g., daring was described as likes to do exciting, scary things). Traits are listed from highest to lowest mean gender difference. Positive values mean that girls valued the trait more than did boys; negative values mean than did boys valued the trait more than did girls

${ }^{\text {a }}$ In-group traits for girls

${ }^{\mathrm{b}}$ Out-group traits for girls

${ }^{c}$ In-group traits for boys

${ }^{\mathrm{d}}$ Out-group traits for boys

\begin{tabular}{|c|c|c|c|}
\hline \multirow[t]{2}{*}{ Trait name } & \multicolumn{2}{|c|}{ Importance ratings } & \multirow[t]{2}{*}{ Mean difference } \\
\hline & Girls $(n=36)$ & Boys $(n=45)$ & \\
\hline Affectionate & $4.75(1.42)$ & $3.60(1.68)$ & 1.15 \\
\hline Gentle $^{\mathrm{d}}$ & $5.97(1.06)$ & $4.91(1.59)$ & 1.06 \\
\hline Fair $^{\text {ad }}$ & $6.61(.60)$ & $5.62(1.09)$ & .99 \\
\hline Helpful ${ }^{\text {ad }}$ & $6.41(.73)$ & $5.48(1.21)$ & .93 \\
\hline Polite ${ }^{\text {ad }}$ & $6.56(.84)$ & $5.71(1.44)$ & .84 \\
\hline Shares $^{\mathrm{a}}$ & $6.22(1.07)$ & $5.57(1.09)$ & .65 \\
\hline Honest & $6.36(1.20)$ & $5.88(1.39)$ & .48 \\
\hline Does things right & $5.61(1.46)$ & $5.20(1.31)$ & .41 \\
\hline Excitable & $5.22(1.53)$ & $4.81(1.64)$ & .41 \\
\hline Daring $^{\text {bc }}$ & $5.15(1.26)$ & $5.56(1.75)$ & -.41 \\
\hline Dependable & $6.33(1.21)$ & $5.93(1.34)$ & .40 \\
\hline Funny ${ }^{\text {bc }}$ & $6.25(.87)$ & $5.91(1.23)$ & .34 \\
\hline Careful & $6.08(1.00)$ & $5.77(1.15)$ & .31 \\
\hline Strong $^{\text {bc }}$ & $5.63(1.17)$ & $5.89(1.24)$ & -.26 \\
\hline Mature & $5.06(1.51)$ & $4.89(1.53)$ & .17 \\
\hline Independent & $5.22(1.53)$ & $5.14(1.56)$ & .08 \\
\hline Confident ${ }^{\text {bcd }}$ & $5.86(1.20)$ & $5.80(1.01)$ & .06 \\
\hline Smart ${ }^{\text {ac }}$ & $6.06(1.12)$ & $6.00(1.06)$ & .06 \\
\hline Ambitious ${ }^{\mathrm{b}}$ & $5.53(1.42)$ & $5.55(1.58)$ & -.02 \\
\hline
\end{tabular}

perceptions of which traits describe girls and which traits describe boys. Analyses revealed a trend-level gender difference in participants' ratings of how well the traits describe girls, Wilks' $\lambda=.66, F(19,61)=1.67, p=.07$, partial $\eta^{2}=.34$, and no gender difference in participants' ratings of how well the traits describe boys, Wilks' $\lambda=.68, F(19,61)=$ 1.51 , ns (means and standard deviations for each trait are presented separately by gender in Tables 2 and 3).

To facilitate testing our hypotheses, we created two scales for each gender. The traits used in each scale were selected from participants' responses to the gender descriptiveness questionnaire. Specifically, we included the five traits that participants saw as most descriptive of girls and the five traits that participants saw as most descriptive of boys. This was done separately by gender, such that each gender had their own in-group scale and their own out-group scale. For girls, the traits included in the in-group scale were smart, fair, shares, helpful, and polite $(\alpha=.70)$, and the traits included in the out-group scale were daring, strong, ambitious, confident, and funny ( $\alpha=.65)$. For boys, the traits included in the in-group scale were daring, strong, funny, confident, and smart $(\alpha=.73)$, and the traits included in the out-group scale were confident, polite, gentle, helpful, and fair $(\alpha=.71)$. Next, we created a composite trait importance rating for each scale, which was done by averaging the participants' importance ratings of the traits comprising each scale. These scales were used as our measure of in-group and out-group traits in our subsequent analyses.

\section{Main Analyses}

Our first hypothesis was that participants would value positive in-group traits more than positive out-group traits. To test this hypothesis, we used paired-sample $t$-tests to compare participants' importance ratings of in- and out-group traits. In line with this hypothesis, girls rated in-group traits $(M=6.37$, $S D=.56)$ as significantly more important to have than outgroup traits $(M=5.69, S D=.76), t(35)=4.94, p<.001, d=.83$. Similarly, boys rated in-group traits $(M=5.83, S D=.82)$ as significantly more important to have than out-group traits $(M=$ 5.51, $S D=.84), t(44)=2.07, p<.05, d=.30$. Taken together, these results suggest that girls and boys do have a tendency to value positive in-group traits more than positive out-group traits.

Hypothesis 2 was that participants with a high proportion of same-gender peers (hi-SGF) would value in-group traits more than would participants with a low proportion of same-gender peers (lo-SGF). To test this hypothesis, participants were first divided into groups depending on their proportion of same-gender friends to total friends. A median split was set at .75 for boys and .57 for girls. These proportions are consistent with the finding that boys tend to have stronger same-gender peer preferences than do girls (see Maccoby 1998). The number of hi- and lo-SGF girls and boys is presented separately by geographic region in Table 4. Participants of different ethnicities were generally evenly represented amongst the hi- and lo-SGF groups. 
Table 2 Mean (SD) ratings of how well each trait describes girls as a function of participant gender

\begin{tabular}{|c|c|c|c|}
\hline \multirow[t]{2}{*}{ Trait name } & \multicolumn{2}{|c|}{ Descriptiveness of girls } & \multirow[t]{2}{*}{ Mean difference } \\
\hline & Girls $(n=36)$ & Boys $(n=45)$ & \\
\hline Strong $^{\mathrm{bc}}$ & $3.23(3.23)$ & $2.22(1.02)$ & 1.01 \\
\hline Daring $^{\text {bc }}$ & $3.17(1.18)$ & $2.31(1.12)$ & .86 \\
\hline Smart ${ }^{\mathrm{ac}}$ & $4.00(.96)$ & $3.31(1.16)$ & .69 \\
\hline Affectionate & $2.40(1.22)$ & $2.96(1.62)$ & -.56 \\
\hline Funny ${ }^{\text {bc }}$ & $3.51(1.13)$ & $3.00(1.19)$ & .51 \\
\hline Fair $^{\text {ad }}$ & $3.86(.93)$ & $3.38(1.28)$ & .48 \\
\hline Dependable & $3.56(1.21)$ & $3.09(1.36)$ & .47 \\
\hline Shares $^{\mathrm{a}}$ & $3.81(.95)$ & $3.36(1.26)$ & .45 \\
\hline Helpful $^{\text {ad }}$ & $3.68(.85)$ & $3.42(1.11)$ & .26 \\
\hline Ambitious ${ }^{\mathrm{b}}$ & $3.50(1.10)$ & $3.25(1.18)$ & .25 \\
\hline Mature & $3.03(1.40)$ & $2.80(1.20)$ & .23 \\
\hline Careful & $3.53(1.18)$ & $3.33(1.21)$ & .20 \\
\hline Excitable & $3.00(1.39)$ & $2.84(1.19)$ & .16 \\
\hline Does things right & $3.00(1.17)$ & $2.87(1.36)$ & .13 \\
\hline Confident ${ }^{\text {bcd }}$ & $3.44(1.16)$ & $3.57(1.14)$ & -.13 \\
\hline Honest & $3.19(1.14)$ & $3.14(1.27)$ & .05 \\
\hline Independent & $2.86(1.25)$ & $2.82(1.40)$ & .04 \\
\hline Polite $^{\text {ad }}$ & $3.58(1.18)$ & $3.56(1.07)$ & .02 \\
\hline Gentle $^{\mathrm{d}}$ & $3.44(1.21)$ & $3.42(1.41)$ & .02 \\
\hline
\end{tabular}

Traits were rated on a scale ranging from 1 (the trait describes almost no girls) to 5 (the trait describes almost all girls). Powlishta (1995) translated the personality traits into "kid friendly" language (e.g., daring was described as likes to do exciting, scary things).Traits are listed from highest to lowest mean gender difference. Negative values mean that male participants rated the trait as more descriptive of girls than did female participants; positive values mean that female participants rated the trait as more descriptive of girls than did male participants

${ }^{a}$ In-group traits for girls

${ }^{b}$ Out-group traits for girls

${ }^{c}$ In-group traits for boys

${ }^{\mathrm{d}}$ Out-group traits for boys

We used one-way analyses of variance (ANOVAs) to compare hi- and lo-SGF participants' trait importance ratings. Analyses for the girls did not support our hypothesis: Hi-SGF girls' ratings of in-group traits $(M=$ $6.42, S D=.67)$ were not significantly different from loSGF girls' ratings $(M=6.33, S D=.44), F(1,33)=.23$, $n s$. Similarly, hi-SGF boys' ratings of in-group traits $(M=$ $5.75, S D=1.00)$ were not significantly different from loSGF boys' ratings $(M=5.85, S D=.60), F(1,40)=.14, n s$. These results suggest that participants' proportion of same-gender friends is not related to their ratings of ingroup traits.

Hypothesis 3 was that hi-SGF participants would devalue out-group traits more than would lo-SGF participants. Similar to the previous analyses, we used one-way ANOVAs to compare hi- and lo-SGF participants' trait importance ratings. Results for the girls did not support our hypothesis: Hi-SGF girls' ratings of outgroup traits $(M=5.63, S D=.84)$ were not significantly different from lo-SGF girls' ratings $(M=5.14, S D=.88), F$
$(1,34)=.12, n s$. Results for the boys, however, did support our hypothesis: Hi-SGF boys' ratings of out-group traits $(M=5.14, S D=.88)$ were significantly lower than lo-SGF boys' ratings $(M=5.77, S D=.62), F(1,40)=7.19, p=.01$. To examine which traits were driving this pattern, we conducted five one-way ANOVAs to compare hi- and loSGF boys' ratings of the five traits that comprise their out-group scale (i.e., confident, polite, gentle, helpful, and fair). Because we were conducting multiple comparisons, we used a Bonferroni adjustment to correct for the heightened likelihood of committing a Type 1 error and set the alpha at .01. Results of the ANOVAs revealed significant differences between hi- and lo-SGF boys' ratings of traits helpful and gentle (see Table 5). In sum, it appears that boys with a high proportion of same-gender friends tend to derogate feminine-stereotyped traits more than do boys with a low proportion of same-gender friends. This difference appears to be largely driven by differences in the boys' ratings of the traits helpful and gentle. 
Table 3 Mean (SD) Ratings of How Well Each Trait Describes Boys as a Function of Participant Gender

\begin{tabular}{|c|c|c|c|}
\hline \multirow[t]{2}{*}{ Trait name } & \multicolumn{2}{|c|}{ Descriptiveness of boys } & \multirow[t]{2}{*}{ Mean difference ${ }^{a}$} \\
\hline & Girls $(n=36)$ & Boys $(n=45)$ & \\
\hline Dependable & $2.67(1.19)$ & $3.56(.99)$ & -.89 \\
\hline Fair $^{\text {ad }}$ & $2.67(1.22)$ & $3.49(.99)$ & -.82 \\
\hline Polite ${ }^{\text {ad }}$ & $2.33(1.10)$ & $3.11(1.21)$ & -.78 \\
\hline Funny $^{\text {bc }}$ & $3.00(1.15)$ & $3.76(.96)$ & -.76 \\
\hline Honest & $2.72(1.19)$ & $3.47(1.06)$ & -.75 \\
\hline Mature & $2.22(1.24)$ & $2.87(1.29)$ & -.65 \\
\hline Smart $^{\text {ac }}$ & $2.94(1.11)$ & $3.57(.86)$ & -.63 \\
\hline Independent & $2.44(1.05)$ & $3.00(1.26)$ & -.56 \\
\hline Shares $^{\mathrm{a}}$ & $2.78(1.29)$ & $3.29(1.08)$ & -.51 \\
\hline Confident $^{\text {bcd }}$ & $3.11(1.04)$ & $3.60(.99)$ & -.49 \\
\hline Helpful $^{\text {ad }}$ & $2.77(1.12)$ & $3.22(1.13)$ & -.45 \\
\hline Does things right & $2.28(.94)$ & $2.69(1.18)$ & -.41 \\
\hline Gentle $^{\mathrm{d}}$ & $2.29(1.03)$ & $2.70(1.08)$ & -.41 \\
\hline Strong ${ }^{b c}$ & $3.72(1.34)$ & $4.07(.99)$ & -.35 \\
\hline Careful & $2.58(1.24)$ & $2.91(1.18)$ & -.33 \\
\hline Ambitious $^{\mathrm{b}}$ & $3.31(1.21)$ & $3.09(1.08)$ & .22 \\
\hline Affectionate & $1.53(.97)$ & $1.42(.66)$ & .11 \\
\hline Daring $^{\text {bc }}$ & $4.11(1.12)$ & $4.09(1.02)$ & .02 \\
\hline Excitable & $2.86(1.25)$ & $2.84(1.33)$ & .02 \\
\hline
\end{tabular}

Traits were rated on a scale ranging from 1 (the trait describes almost no boys) to 5 (the trait describes almost all boys). Powlishta (1995) translated the personality traits into "kid friendly" language (e.g., daring was described as likes to do exciting, scary things). Traits are listed from highest to lowest mean gender difference. Negative values mean that male participants rated the trait as more descriptive of boys than did female participants; positive values mean that female participants rated the trait as more descriptive of boys than did male participants

${ }^{a}$ In-group traits for girls

${ }^{\mathrm{b}}$ Out-group traits for girls

${ }^{c}$ In-group traits for boys

${ }^{\mathrm{d}}$ Out-group traits for boys

\section{Discussion}

The purpose of the present study was to attain a better understanding of children's same-gender favoritism. The relationship between intergroup processes such as in-group favoritism and children's gender development is a topic that has received increasing attention in the research literature (e.g., Bigler and Liben 2007; Leaper 2000; Maccoby 1998; Powlishta 2004). Therefore, a better understanding of children's same-gender favoritism may afford a deeper understanding of children's gender typing and adherence to gender roles.

One goal of the present study was to replicate and extend past research on children's same-gender favoritism. Past
Table 4 Number of participants in the high- and low-samegender-friends (SGF) groups as a function of gender and geographic location

Four participants were excluded from these analyses due to missing data

\begin{tabular}{llll}
\hline Participant gender & \multicolumn{2}{l}{ Geographic region } & Total $(N=77)$ \\
\cline { 2 - 4 } & Midwest $(n=17)$ & West Coast $(n=60)$ & \\
\hline Male $(n=42)$ & 4 & & 22 \\
$\quad$ Hi-SGF & 4 & 18 & 20 \\
Lo-SGF & & 16 & 18 \\
Female $(n=35)$ & 6 & 12 & 17 \\
Hi-SGF & 3 & 14 & \\
Lo-SGF & & & \\
\hline
\end{tabular}


Table 5 Importance ratings of feminine-stereotyped traits among boys in the high- and low-same-gender-friends (SGF) groups

\begin{tabular}{lllll}
\hline Trait & M (SD) & df & F & p \\
\hline Gentle & & 41 & 8.45 & .006 \\
Lo-SGF Boys $(n=20)$ & $5.55(1.10)$ & & & \\
Hi-SGF Boys $(n=22)$ & $4.22(1.74)$ & & & \\
Helpful & & 41 & 8.00 & .007 \\
Lo-SGF Boys $(n=20)$ & $5.95(1.00)$ & & & \\
Hi-SGF Boys $(n=22)$ & $4.95(1.25)$ & & & \\
Polite & & 41 & 3.60 & .065 \\
Lo-SGF Boys $(n=20)$ & $6.05(1.23)$ & & & \\
Hi-SGF Boys $(n=22)$ & $5.23(1.54)$ & & & \\
Fair & & 41 & .75 & .393 \\
Lo-SGF Boys $(n=20)$ & $5.70(.73)$ & & & \\
Hi-SGF Boys $(n=22)$ & $5.41(1.33)$ & & & \\
Confident & & 41 & .70 & .407 \\
Lo-SGF Boys $(n=20)$ & $5.60(.99)$ & & & \\
Hi-SGF Boys $(n=22)$ & $5.86(1.04)$ & & & \\
\hline
\end{tabular}

Ratings were made on a scale ranging from 1 (the trait is very bad to have) to 7 (the trait is very good to have)

research using the trait assignment paradigm (Powlishta et al. 1994; Powlishta 1995; Silvern 1977; Susskind and Hodges 2007; Zalk and Katz 1978) has demonstrated that children tend to show same-gender favoritism through their allocation of personality traits to the two genders. Results consistently show that children tend to allocate more positive traits to their own gender than to the other gender (e.g., Powlishta 1995; Susskind and Hodges 2007). Rather than examining the relative number of positive traits that boys and girls allocate to one another, the present study took a somewhat different approach to examining children's same-gender favoritism. Specifically, we examined whether children value the positive traits they perceive to be descriptive of their own gender more than the traits they perceive to be descriptive of the other gender. In line with our first hypothesis, both boys and girls valued the traits perceived to be descriptive of their own gender significantly more than the traits perceived to be descriptive of the other gender.

This finding is interesting for several reasons. First, it suggests that when children make their trait allocations, they are not solely focusing on the traits' degree of positivity. Rather, it appears that they also consider how important each trait is for members of their gender to possess. This is a finding that cannot be ascertained by the traditional trait assignment methodology. These findings also suggest that there is a distinction between asking children "How positive or negative is this trait?" versus "How good or bad is it to have this trait if members of your gender want to feel good about themselves?" To elaborate,
Powlishta (1995) asked third and fourth grade children to rate personality traits along a positivity-negativity spectrum and found virtually no significant gender differences in her sample's positivity-negativity ratings. In contrast, the children in the present study rated how important each trait is for their gender to possess, which did elicit a significant overall gender difference.

The finding that children valued same-gender traits more than other-gender traits is consistent with research on children's gender schemas (e.g., Martin et al. 1995; see also Martin et al. 2002), which typically demonstrates that children are motivated to adhere to characteristics that define their gender. This argument complements social identity theory (Aberson et al. 2000; Tajfel and Turner 1986), which proposes that people should want to assimilate the characteristics that make their in-group distinct from other groups. In support of these points, Martin and colleagues (1995) labeled unfamiliar toys as either "for boys" or "for girls" and found that preschool children preferred to play with the toys that they thought were for their own gender. This study shows that children's gender schemas shape not only their attitudes, but also their behaviors and choices (see also Martin and Fabes 2001; Fabes et al. 2003). Therefore, children who derogate crossgender traits in trait assignment studies, such as the hi-SGF boys in the present study, may also avoid enacting crossgender traits in their daily lives.

Our second and third hypotheses tested the prediction that children's exposure to same-gender peers would be related to their display of same-gender favoritism. According to social identity theory (Tajfel and Turner 1986; Turner and Reynolds 2004), people are motivated to adhere to the norms that characterize the groups to which they belong. Because the norms of children's same-gender peer groups are typically consistent with traditional gender norms, some researchers argue that children's same-gender peer groups play a critical role in gender socialization (Leaper 2000; Leaper and Friedman 2007; Maccoby 1998; Powlishta 2004). To test this prediction, we compared the trait ratings of participants with a high proportion of same-gender friends (hi-SGF) to those of participants with a low proportion of same-gender friends (lo-SGF). When we compared hi- and lo-SGF participants' ratings of the positive in-group traits, we did not find significant differences for either gender. However, when we compared hiand lo-SGF participants' ratings of the positive out-group traits, we found that hi-SGF boys rated the positive feminine-stereotyped traits significantly lower than did the lo-SGF boys. In other words, hi-SGF boys perceived the positive feminine-stereotyped traits as significantly less important to have than did the lo-SGF boys. Because boys' proportion of same-gender friend was not related to their ratings of positive masculine-stereotyped traits, it may be 
that their bias manifests itself as out-group derogation rather than in-group favoritism per se.

To explain why this pattern of findings occurred for boys, we turn to literature on the rigidity of the male gender role. By the time children are 3 years old, they are already knowledgeable about basic stereotypes pertaining males and females (Kuhn et al. 1978; Weinraub et al. 1984; Zenmore et al. 2000). Research shows that both boys and girls who contradict traditional gender roles are evaluated somewhat negatively (Blakemore 2003; Martin 1989; Meece 1987). However, boys who act like girls typically receive more criticism than girls who act like boys (Fagot et al. 2000), and are perceived more negatively by other boys (Langlois and Downs 1980; Zucker et al. 1995) and by their parents (Langlois and Downs 1980). Because of this treatment, boys might be highly motivated to avoid positive feminine-stereotyped traits in order to appear more masculine (Powlishta 2004; Leaper and Friedman 2007). Indeed, the hi- and lo-SGF boys differed most in their ratings of the traits gentle and helpful, which are two traits that children and adults rate as highly feminine-stereotyped (e.g., Martin 1995; Powlishta 1995).

Because the male gender role is often strictly enforced within male peer groups (Leaper 1994; Maccoby 1998), it may be that boys with many same-gender friends adhere especially strongly to gender norms. Boys in particular tend to become more gender-typed in their behavior as their exposure to same-gender peers increases (Maccoby 1998; Munroe and Romney 2006). This tendency is probably related to the finding that the male gender role is more rigid than the female gender role (Archer 1984; Bussey and Bandura 1999). Some researchers have argued that this rigidity is due to a general tendency for males to be higher in social status than females (Leaper 2000; Wood and Eagly 2002), which means that males risk losing status within their peer group if they behave in a cross-gender-typed manner. Therefore, it is plausible that socialization practices in male-dominated peer groups may lead some boys to develop negative attitudes about females and femininity. Although this particular claim has yet to be examined in elementary school children, Martin and Fabes (2001) did note that children in preschool became more gender-typed in their behavior with increased exposure to same-gender peers.

The relationship between membership in male-dominated peer groups and the rejection of femininity has also been examined by researchers who study all-male athletic teams in high schools and colleges (e.g., Anderson 2008; Schacht 1996). These studies tend to demonstrate that team members who display feminine-stereotyped behaviors (e.g., crying) are frequently ostracized. Furthermore, words associated with femininity are often used between teammates as insults (e.g., "You throw like a girl!"). Feminine-stereotyped traits are also undervalued in the workforce. Both the percentage of women in a field (Cohen and Huffman 2003; England et al. 1994) and fields that necessitate the feminine-stereotyped quality of nurturance (England et al. 1994) are related to lower pay for workers. Echoing our own findings, the devaluing of women's work is greatest in male-dominated labor markets in which men interact primarily with other men (Cohen and Huffman 2003).

\section{Limitations and Future Directions}

One limitation of the current research is that testing the participants in mixed-gender groups may have influenced the findings by heightening the salience of gender for participants. Enhanced gender salience has been linked to the perception of greater between-gender differences and a greater likelihood of adherence to gender norms (Hannover 2000). Therefore, participants' trait allocations and their ratings of trait importance could have been influenced by being in a mixed-gender group. It is important to note, however, that although increased gender salience could have enhanced the robustness of the findings, it is unlikely the overall pattern of results would have been altered by testing participants individually. This is because the content of the questionnaires themselves probably served to make gender salient for the participants.

A second limitation is the lack of diversity in our sample. Our participants were relatively homogeneous in terms of ethnicity and socioeconomic status, which may reduce the extent to which our results generalize to other groups. Furthermore, we investigated children from two different geographic locations, which could have influenced their responses to the questionnaires. That said, the phenomena under investigation in this study (i.e., samegender favoritism and same-gender peer preferences) have been displayed by children living in a variety of cultural contexts (Maccoby 1998; Munroe and Romney 2006).

Finally, several methodological aspects of our study present potential limitations. The first of these limitations pertains to the wording of the trait importance questionnaire ("If girls [boys] want to feel good about themselves, how good or bad is it to be like this?"). It may be that our word choice of "good or bad" conflates the valence of the traits with their importance. Were this the case, it would mean that the questionnaire assessed participants' views of the traits' positivity-negativity, rather than their perceived importance. However, given that our findings were substantially different from those obtained by Powlishta (1995), who asked children about traits' positivitynegativity, we believe that our measure was at least partially successful in assessing a construct distinct from trait valence. The second methodological concern pertains to our measure of children's same- and cross-gender friend- 
ships. Specifically, participants were limited to listing students from their class as friends. Although imposing this constraint afforded several methodological advantages (delineated in Method section), it also meant that the friends children have outside of the classroom were excluded (e.g., friends from other classes, church, or athletic teams). Furthermore, the validity of this measure would have been enhanced if we had cross-referenced participants' lists of friends with lists provided by participants' parents or teachers. In sum, our friendship measure yielded a concrete, yet potentially incomplete, gauge of children's friendship groups. Future research in this domain should endeavor to measure children's same- and cross-gender friendships with more thorough and diverse methodologies. Lastly, we wish to note that the Cronbach's alpha for the girls' out-group scale was lower than is conventionally viewed as acceptable ( $\alpha=.65$ vs. $\alpha=.70$ ), so analyses using this scale should be interpreted with this in mind.

Although exposure to same-gender peers was not associated with girls' display of same-gender favoritism in the present study, there are probably other factors that do relate to girls' same-gender favoritism (see Powlishta 2004). Future research should attempt to elucidate some of these factors. In particular, investigating girls' perceptions of males' and females' relative positions in the social hierarchy could prove a fruitful avenue for future research. Research shows that by late elementary school, most children are well aware that males tend to have more power and are of higher status than females (e.g., Glick and Hilt 2000). According to social identity theory (Abrams et al. 2003; Tajfel and Turner 1986; Turner et al. 1979), this status differential could elicit strong same-gender favoritism in girls if they perceive their lower status to be unstable and illegitimate (see Bettencourt et al. 2001, for a metaanalysis). That is, girls may seek to combat boys' higher status through heightened in-group bias. Furthermore, girls' lower status could serve to make their gender more salient (Hannover 2000), thus increasing their identification with the in-group. Social identity theory would predict that this too should contribute to girls' strength of same-gender favoritism. Therefore, future research should examine children's understanding of the social hierarchy and assess whether individual differences in this understanding predict the strength of girls' same-gender favoritism.

Future research should also investigate the causal relationship between membership in male-dominated peer groups and the rejection of feminine-stereotyped attributes. The present research demonstrated that a relationship between these two factors exists, but it may be that boys who seek out male-dominated peer groups already have negative attitudes about femininity. A longitudinal design would provide insight into this question by allowing researchers to examine whether boys' tendency to reject femininity increases along with their exposure to samegender friends. Furthermore, a long-term longitudinal study would provide insight into whether the negative attitudes about femininity that some males display in adolescence and adulthood have their roots in the peer socialization experienced during childhood.

\section{Concluding Remarks}

The present study built upon past research in several ways. First, the results expand on past trait assignment research by examining whether same-gender favoritism manifests itself in children's ratings of trait importance. Consistent with hypotheses, both boys and girls rated same-gender traits as more important to possess than other-gender traits. In addition, this study is the first, to our knowledge, to link boys' rejection of feminine-stereotyped traits to their same-gender friendship preferences. The finding that boys with a high proportion of same-gender friends rejected the positive femininestereotyped traits suggests that male-dominated peer groups may play a role in socializing the negative attitudes about femininity that some males display later in life.

Acknowledgement This research was funded by NIH predoctoral training grant T32 HD46423. We thank Margarita Azmitia and Campbell Leaper for their helpful comments on earlier versions of this manuscript. We also thank the Santa Cruz County School District for allowing data collection in their schools and Ashley Andrew and Ryan Puhrmann for their assistance with data collection. These data were presented at the 2008 Gender Development Research Conference in San Francisco, CA and at the 2009 Society for Research in Child Development Conference in Denver, CO.

Open Access This article is distributed under the terms of the Creative Commons Attribution Noncommercial License which permits any noncommercial use, distribution, and reproduction in any medium, provided the original author(s) and source are credited.

\section{References}

Aberson, C. L., Healy, M. R., \& Romero, V. L. (2000). Ingroup bias and self-esteem: A meta-analysis. Personality and Social Psychology Review, 4, 157-173.

Abrams, D., Rutland, A., Cameron, L., \& Marques, J. M. (2003). The development of subjective group dynamics: When in-group bias gets specific. British Journal of Developmental Psychology, 21, $155-176$.

Anderson, E. (2008). 'I used to think women were weak': Orthodox masculinity, gender segregation, and sport. Sociological Forum, 23, 257-280.

Archer, J. (1984). Gender roles as developmental pathways. British Journal of Social Psychology, 23, 245-256.

Banaji, M. R., \& Prentice, D. A. (1994). The self in social contexts. Annual Review of Psychology, 45, 297-332. 
Bettencourt, B. A., Dorr, N., Charlton, K., \& Hume, D. L. (2001). Status differences an in-group bias: A meta-analytic examination of the effects of status stability, status legitimacy, and group permeability. Psychological Bulletin, 127, 520-542.

Bigler, R. S. (1995). The role of classification skill in moderating environmental influences on children's gender stereotyping: A study of the function use of gender in the classroom. Child Development, 66, 1072-1087.

Bigler, R. S., \& Liben, L. S. (2007). Developmental intergroup theory: Explaining and reducing children's social stereotyping and prejudice. Current Directions in Psychological Science, 16, $162-166$.

Bigler, R. S., Jones, L. C., \& Lobliner, D. B. (1997). Social categorization and the formation of intergroup attitudes in children. Child Development, 68, 530-543.

Blakemore, J. E. O. (2003). Children's beliefs about violating gender norms: Boys shouldn't look like girls, and girls shouldn't act like boys. Sex Roles, 48, 411-419.

Brewer, M. B. (1999). The psychology of prejudice: Ingroup love or outgroup hate? Journal of Social Issues, 55, 429-444.

Bussey, K., \& Bandura, A. (1999). Social cognitive theory of gender development and differentiation. Psychological Review, 106, 676-713.

Cohen, P. N., \& Huffman, M. L. (2003). Occupational segregation and the devaluation of women's work across U. S. Labor markets. Social Forces, 81, 881-908.

England, P., Herbert, M. S., Kilbourne, B. S., \& Megdal, L. M. (1994). The gendered valuation of occupations and skills: Earnings in 1980 Census occupations. Social Forces, 73, 65-100.

Fabes, R. A., Martin, C. L., Hanish, L. D., Anders, M. C., \& MaddenDerdich, D. A. (2003). Early school competence: The roles of sexsegregated play and effortful control. Developmental Psychology, $39,848-858$.

Fagot, B. I., Rodgers, C. S., \& Leinbach, M. D. (2000). Theories of gender socialization. In T. Eckes \& H. M. Trautner (Eds.), The developmental social psychology of gender (pp. 65-89). Mahwah: Lawrence Erlbaum.

Glick, P., \& Hilt, L. (2000). Combative children to ambivalent adults: The development of gender prejudice. In T. Eckes \& H. M. Trautner (Eds.), The developmental social psychology of gender (pp. 243-272). Mahwah: Lawrence Erlbaum.

Hannover, B. (2000). Development of the self in gendered contexts. In T. Eckes \& H. M. Trautner (Eds.), The developmental social psychology of gender (pp. 177-206). Mahwah: Lawrence Erlbaum.

Harris, J. R. (1995). Where is the child's environment? A group socialization theory of development. Psychological Review, 102, 458-489.

Houston, D. M., \& Andreopoulou, A. (2003). Tests of both corollaries of social identity theory's self-esteem hypothesis in real group settings. British Journal of Social Psychology, 42, $357-370$.

Kuhn, D., Nash, S., \& Brucken, L. (1978). Sex role concepts of twoand three-year-olds. Child Development, 49, 445-451.

Lalonde, R. N. (1992). The dynamics of group differentiation in the face of defeat. Personality and Social Psychology Bulletin, 18, 336-342.

Langlois, J. H., \& Downs, C. A. (1980). Mothers, fathers, and peers as socialization agents of sex-typed play behaviors in young children. Child Development, 51, 1237-1247.

Leaper, C. (1994). Exploring the consequences of gender segregation on social relationships. In C. Leaper (Ed.), Childhood gender segregation: Causes and consequences. New directions for child development (pp. 67-86). San Francisco: Jossey-Bass.

Leaper, C. (2000). The social construction and socialization of gender during development. In P. Miller \& E. Scholnick (Eds.), Toward a feminist developmental psychology (pp. 127-152). New York: Routledge.

Leaper, C., \& Friedman, C. K. (2007). The socialization of gender. In J. E. Grusec \& P. D. Hastings (Eds.), Handbook of socialization: Theory and research (pp. 561-587). New York: Guilford Press.

Maccoby, E. E. (1998). The two sexes: Grouping up apart, coming together. Cambridge: Harvard University Press.

Maccoby, E. E., \& Jacklin, C. N. (1987). Gender segregation in children. In H. W. Reece (Ed.), Advances in child development and behavior (pp. 239-287). New York: Academic.

Martin, C. L. (1989). Children's use of gender-related information in making social judgments. Developmental Psychology, 25, 80-88.

Martin, C. L. (1995). Stereotypes about children with traditional and nontraditional gender roles. Sex Roles, 33, 727-751.

Martin, C. L., \& Halverson, C. F. (1981). A schematic processing model of sex typing and stereotyping in children. Child Development, 52, 1119-1134.

Martin, C. L., \& Fabes, R. A. (2001). The stability and consequences of young children's same-sex peer interactions. Developmental Psychology, 37, 431-446.

Martin, C. L., Eisenbud, L., \& Rose, H. (1995). Children's genderbased reasoning about toys. Child Development, 66, 1453-1471.

Martin, C. L., Ruble, D. N., \& Szkrybalo, J. (2002). Cognitive theories of early gender development. Psychological Bulletin, $128,903-933$.

Meece, J. L. (1987). The influences of school experiences on the development of gender schemata. In L. Liben \& M. Signorella (Eds.), Children's gender schemata (pp. 57-69). San Francisco: Jossey-Bass.

Mehta, C. M., \& Strough, J. (2009). Sex segregation in friendships and normative contexts across the lifespan. Developmental Review, 29, 201-220.

Munroe, R. L., \& Romney, A. K. (2006). Gender and age differences in same-sex aggregation and social behavior: A four culture study. Journal of Cross-Cultural Psychology, 37, 3-19.

Powlishta, K. K. (1995). Gender bias in children's perceptions of personality traits. Sex Roles, 32, 17-28.

Powlishta, K. K. (2004). Gender as a social category: Intergroup processes and gender-role development. In M. Benett \& F. Sani (Eds.), The development of the social self (pp. 103-133). New York: Psychology.

Powlishta, K. K., Serbin, L. A., Doyle, A. B., \& White, D. R. (1994). Gender, ethnic, and body type biases: The generality of prejudice in childhood. Developmental Psychology, 30, 526-536.

Schacht, S. P. (1996). Misogyny on and off the "pitch": The gendered world of male rugby players. Gender \& Society, 10, 550-565.

Silvern, L. E. (1977). Children's sex-role preferences: Stronger among girls than boys. Sex Roles, 3, 159-171.

Susskind, J. E., \& Hodges, C. (2007). Decoupling children's genderbased in-group positivity from out-group negativity. Sex Roles, $56,707-716$.

Tajfel, H., \& Turner, J. C. (1986). The social identity theory of intergroup behavior. In S. Austin \& W. G. Austin (Eds.), Psychology of intergroup relations (pp. 7-24). Chicago: Nelson Hall.

Turner, J. C., \& Reynolds, K. J. (2004). The social identity perspective in intergroup relations: Theories, themes, and controversies. In M. B. Brewer \& M. Hewstone (Eds.), Self and social identity. Perspectives on social psychology (pp. 259-277). Malden: Blackwell.

Turner, J. C., Brown, R. J., \& Tajfel, H. (1979). Social comparison and group interest in ingroup favoritism. European Journal of Social Psychology, 9, 187-204. 
Vaughan, G. M., Tajfel, H., \& Williams, J. (1981). Bias in reward allocation in an intergroup and an interpersonal context. Social Psychology Quarterly, 44, 37-42.

Verkuyten, M., \& Thijs, J. (2001). Ethnic and gender bias among Dutch and Turkish children in late childhood: The role of social context. Infant and Childhood Development, 10, 203217.

Weinraub, M., Clemens, L. P., Sockloff, A., Ethridge, T., Gracely, E., \& Meyers, B. (1984). The development of sex role stereotypes in the third year: Relationships to gender labeling, gender identity, sex-typed toy preference, and family characteristics. Child Development, 55, 1493-1503.
Wood, W., \& Eagly, A. H. (2002). A cross-cultural analysis of the behavior of women and men: Implications for the origins of sex differences. Psychological Bulletin, 128, 699-727.

Zalk, S. R., \& Katz, P. A. (1978). Gender attitudes in children. Sex Roles, 4, 349-357.

Zenmore, S. E., Fiske, S. T., \& Kim, H. (2000). Gender stereotypes and the dynamics of social interaction. In T. Eckes \& H. M. Trautner (Eds.), The developmental social psychology of gender (pp. 207-241). Mahwah: Lawrence Erlbaum.

Zucker, K. J., Wilson-Smith, D. N., Kurita, J. A., \& Stern, A. (1995). Children's appraisals of sex-typed behavior in their peers. Sex Roles, 33, 703-725. 